\title{
Amber Specimens Reveal Origin of Long Mouthpart of Scorpionflies
}

M esopsychoid scorpionflies are peculiar Mesozoic insects with distinctly elongate mouthparts. and are considered to be a critical group of pollinators prior to the rise of angiosperms.

A new genus found from 99-million-year-old Burmese amber reveals the origin of scorpionflies' long mouthparts. This discovery was reported in Science Advances on March $t$.

Aneuretopsychidae is a family of mecopteran insects with long siphonate mouthparts. In particular, this family is the key to understanding both the early evolution of highly modified mouthparts in Mesopsychoidea and arguably the origin of fleas.

Previously. all known aneuretopsychids were from compression fossils, and the detailed structure of their mouthparts was unclear:

Now, however, an international research group led by Prof. WANG Bo from the Nanjing Institute of Geology and Palaeontology of the Chinese Academy of Sciences (NICPAS) has found a new genus, including two new aneuretopsychid species from early Late Cretaceous (99 million years ago) Burmese amber, which reveals new anatomically significant details of the elongate mouthpart elements.

The aneuretopsychid mouthpart structure as seen in the new amber fossils consists of one pair of galeae and one unpaired central hypopharynx. During feeding. the galeae would come together temporarily and enclose the hypopharynx thus forming a functional tube.

The structures of the new three-dimensionally preserved fossils thus reveal that the aneuretopsychid mouthpart is not labial but maxillary in origin.

The phylogenetic results based on 38 taxa and $5+$ discrete characters support the monophyly of Mesopsychoidea and demonstrate that an elongate mouthpart is one of its key synapomorphies, challenging the view that the long-proboscid condition independently originated two or three times in this clade.

In addition. the mouthpart of Mesopsychoidea

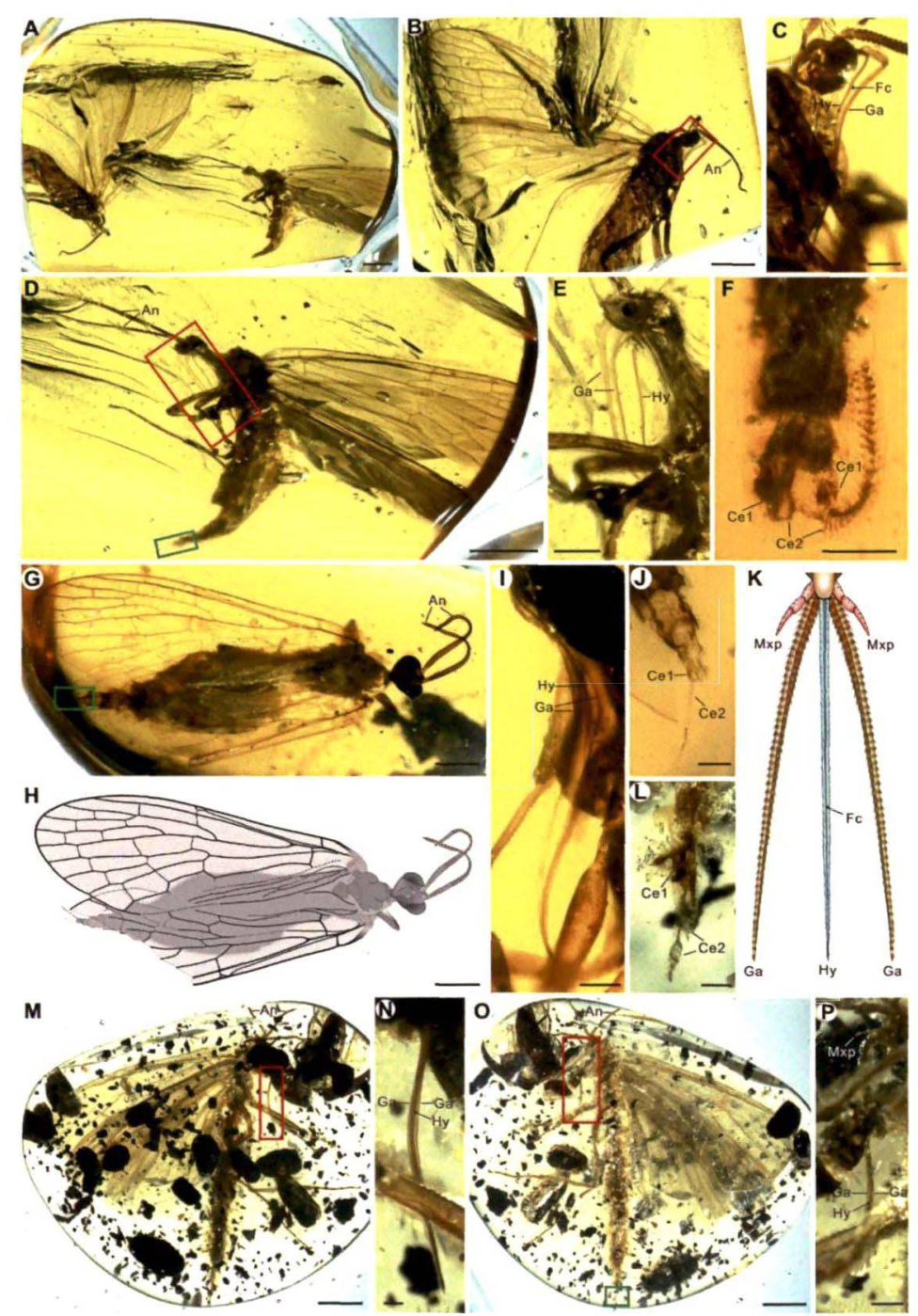

Aneuretopsychidae from Late Cretaceous Burmese amber (Image by NIGPAS)

differs structurally from the highly modified piercing mouthpart of Siphonaptera. So. neither Aneuretopsychidae nor Mesopsychoidea is a sister group to Siphonaptera. 


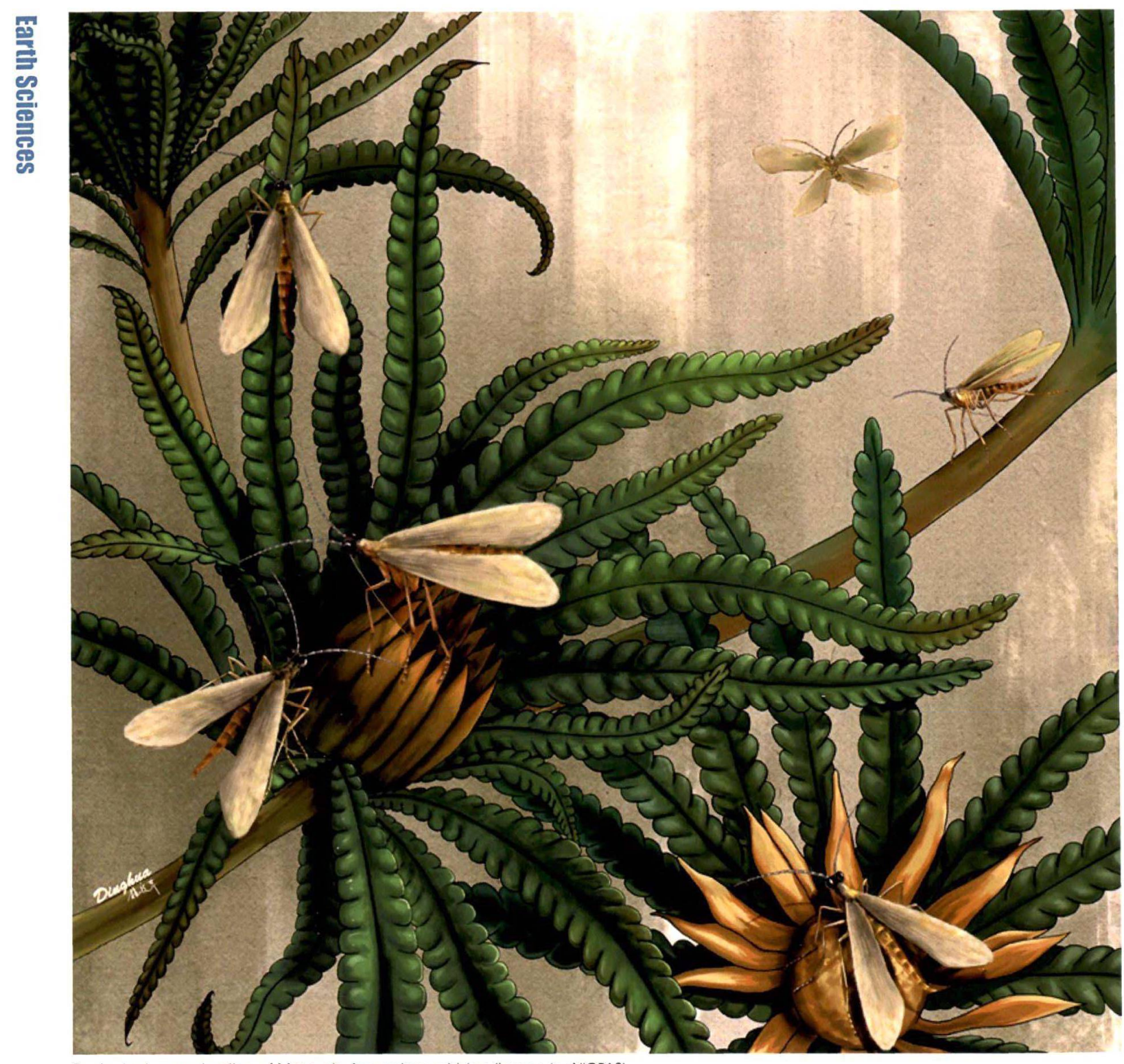

Ecological reconstruction of Mesozoic Aneuretopsychidae (Image by NIGPAS)

In the Burmese amber forest. at least five families of long-proboscid insects have been discovered. further revealing the variety and complexity of mid-Cretaceous pollinating insects.
This study provides new insights into the separate origins of the long mouthpart of Mesopsychoidea and fleas. and the evolution of Cretaceous pollinating insects.

\section{Reference}

Zhao Xiangdong, Wang Bo*, Bashkuev A.S., Aria C., Zhang Qingaing, Zhang Haichun, Tang Wentao, Engel M.S. (2020) Mouthpart homologies and life habits of Mesozoic long-proboscid scorpionflies. Science Advances, 6: eaay 1259. 